\title{
ANALISIS SISTEM PERTAHANAN ZONE PRESS TIM BOLA BASKET PUTERA UNIVERSITAS NEGERI JAKARTA PADA STAN BIG BALL TOURNAMENT 2015
}

\author{
Ahmad Kholil Robbani \\ Iman Sulaiman dan Yasep Setiakarnawijaya
}

\begin{abstract}
ABSTRAK. Penelitian ini bertujuan untuk mengetahui tentang: (1) analisis keberhasilan sistem pertahanan 3-2 zone press. (2) analisis keberhasilan sistem pertahanan 2-3 zone press. (3) analisis keberhasilan sistem pertahanan 2-2-1 full court press. (4) analisis tingkat keberhasilan dari ketiga sistem pertahanan tim bola basket putra Universitas Negeri Jakarta pada STAN BIG BALL TOURNAMENT 2015.

Metode penelitian menggunakan metode deskriptif dengan teknik survey. Instrumen pengambilan data menggunakan tabel-tabel yang berkolom untuk mengetahui keberhasilan dan kegagalan 3-2 zone press, 2-3 zone press, dan 2-2-1 full court press dengan kriteria keberhasilan dan kegagalan. Populasi yang digunakan yaitu seluruh aktivitas bertahan tim bola basket putera UNJ pada STAN Big Ball Tournament 2015, dan sampel dari penelitian ini adalah seluruh aktivitas bertahan menggunakan sistem pertahanan zone press, dengan menggunakan teknik total sampling. Instrumen pengambilan data menggunakan tabel-tabel yang berkolom untuk mengetahui keberhasilan dan kegagalan 3-2 zone press, 2-3 zone press, dan 2-2-1 full court press dengan kriteria keberhasilan dan kegagalan. Pengumpulan data dilakukan untuk mengetahui keberhasilan dan kegagalan sistem pertahanan zone press (3-2 zone press, 2-3 zone press, dan 22-1 full court press), yang selanjutnya akan diperoleh data yang bersifat kuantitatif.

Hasil analisis data dari jumlah sebanyak 6 pertandingan, diperoleh keseluruhan aktifitas 3-2 zone press memperoleh 130 kali percobaan dengan persentase $52,31 \%$ untuk keberhasilan dan 47,69\% untuk kegagalan. Keseluruhan aktifitas 2-3 zone press memperoleh 28 kali percobaan dengan persentase $42,86 \%$ untuk keberhasilan dan $57,14 \%$ mengalami kegagalan, dan yang terakhir sistem 2-2-1 full court press memperoleh 37 kali percobaan dengan persentase $62,16 \%$ untuk keberhasilan dan 37,84\% mengalami kegagalan.
\end{abstract}

\section{Kata Kunci ; Sistem Pertahanan, Zone press, Bola Basket}

Pendahuluan

Ada beberapa faktor yang mempengaruhi prestasi olahraga, diantarnya, faktor fisik, teknik, dan taktik. Faktor taktiklah salah satu yang sangat menentukan dalam meraih prestasi. Dengan menerapkan taktik yang tepat dan sesuai dengan kebutuhan, sebuah tim bola basket dapat memenangkan pertandingan. Taktik yang dimaksud adalah taktik dalam penyerangan dan pertahanan. Seorang pelatih dituntut kreatif dalam membuat sebuah pola penyerangan sehingga tim tersebut dapat mencetak point dengan efektif dan efesien. Begitu pula dengan taktik yang diterapkan seorang pelatih untuk membuat sebuah pertahanan yang kokoh dan kuat sehingga pemain lawan akan sulit mencetak point. Ada sebuah pernyataan "bertahan adalah juara", ini memiliki arti tim yang memiliki pertahanan yang kuat akan menjadi juara. Dalam permainan bola basket dikenal beberapa taktik bertahan diantaranya ialah Man to Man Defense dan Zone Defense. Man to Man Defense atau pertahanan satu lawan satu lawan satu mengharuskan setiap pemain bertahan menjaga atau menempel satu pemain penyerang. Tanggung jawab utama pemain bertahan adalah tidak membiarkan pemain penyerang melakukan dribble-drive menuju ke ring basket atau melakukan jump shoot secara terbuka. Dalam petahanan satu lawan satu dikenal juga dengan istilah help-side defense, situasi ini terjadi apabila ada rekan tim kita yang dikalahkan oleh pemain penyerang, dimana pada saat ini dibutuhkan pemain bertahan yang membantu menutup 
pergerakan pemain penyerang yang berhasil melewati rekan timnya agar pemain tersebut tidak dengan mudah melakukan finishing dengan terbuka.

Selain man to man defense adapula taktik pertahanan daerah atau zone defense, tanggung jawab utama pemain bertahan zona adalah mencegah lawan mencetak angka dari areanya. Ketika bola memasuki area pemain bertahan, maka pemain tersebut harus menggunakan dasar-dasar pertahanan satu lawan satu untuk menghalangi pemain penyerang melakukan dribbling-drive ke ring basket atau melakukan jump shoot terbuka. Pada pertahanan ini juga dikenal taktik pertahanan menekan atau zone press defense, zone press biasa digunakan untuk menghasilkan perpindahan bola akibat umpan yang buruk atau pelanggaran 8 detik, yang keduannya akan menghasilkan bola untuk pemain bertahan.

Ada beberapa jenis zone press defense yang umum digunakan diantaranya zone press defense 1-2-1-1, 2-2-1, 2-3, 3-2, dan 1-3-1 dengan pola pertahanan tersebut pemain bertahan berusaha menciptakan perpindahan bola dengan memaksa lawan untuk mengumpan bola ke dalam ke sudut maupun tepi lapangan, kemudian menjebak pemain penyerang yang sedang menguasai bola. Sebuah jebakan yang berdaya guna bisa menyebabkan pemain bertahan mengacaukan lawan sehingga umpan tidak tepat, bola lepas, atau memaksan timeout, dan semua itu merupakan hasil yang bisa didapatkan oleh tim bertahan. Keberhasilan zone press merupakan sebuah hasil latihan dan ketepatan penempatan pemain bertahan. Semua itu merupakan tugas dari pelatih untuk meramu latihan-latihan zone press dan menempatkan pemain-pemainnya pada pos yang benar sesuai dengan fungsi dan tugas masing-masing.

Dalam penelitian ini subyek adalah tim bola basket putera Universitas Negeri Jakarta. Tim bola basket putra UNJ memang sering menggunakan pola pertahanan zone press, diantaranya seperti 2-2-1 zone pres, 2-3 zone press, dan 2-2-1 full court press, namun sering kali gagal dalam penerapan pola bertahan zone press ini, kegagalan yang sering terjadi seperti pemain penyerang mudah melakukan long pass, pemain penyerang mudah melewati setengah lapangan dengan cepat, dan yang paling fatal ialah pemain penyerang dapat melakukan long pass ke pemain penyerang lainnya yang berada dekat dengan ring pemain bertahan. Ini merupakan permasalahan yang dialami oleh pelatih, kalau dilihat dari prosesnya, semua tugas dan pergerakan pemain bertahan pada pola zone press ini telah dilatih dan terus dilakukan berulang kali.

\section{SISTEM DEFENSE}

Bertahan dan menyerang merupakan bagian dari setiap cabang olahraga permainan yang menggunakan bola besar atau kecil. Dalam permainan bola basket di kenal dengan orientasi bertahan sama dengan juara. Biasanya tim dengan orientasi bertahan memenangkan kejuaraan karena mampu membaca beberapa peluang mencetak angka yang diperoleh lawannya selama pertandingan. Tim NBA, Detroit Pistons, pernah menjadi contoh keunggulan pertahanan sebuah tim, mereka amat merepotkan lawanlawannya dalam setiap tembakan, dan jarang memberi kesempatan mencetak angka dengan mudah. Dengan kata lain bertahan merupakan usaha yang maksimal agar pemain penyerang tidak mencetak point dengan mudah. Namun keberhasilan pertahanan secara keseluruhan tergantung pada setiap pemain bertahan yang memiliki dasar-dasar pertahanan individu yang sangat baik, bugar secara jasmani, dan sangat atletis.

Filosofi defense setiap pelatih boleh saja berbeda, atau sama dengan yang lainnya, namun hal ini tidaik menjadikan sebuah defense dianggap terbaik dibandingkan defense yang lainnya. Hal-hal yang dapat membedakan sebuah defense antara lain, materi pemain, kemampuan/keterampilan individu pemain, kejelian pelatih dalam merancang, memberikan dan mengoreksi sebuah defense, dan lain sebagainya. Pada intinya ketika pelatih ingin menerapkan sebuah defense boleh saja pelatih menyesuaikan dengan filosofi dirinya, namun kembali lagi 
kebutuhan kebutuhan tim, dan karakter pemain yang sudah terbentuk harus menjadi perhatian seorang pelatih. Setelah sudah menentukan defense apa yang ingin diterapkan, barulah pelaith mulai secara perlahan untuk memberika latihan terkait defense yang akan diberikan.

Ada sembilan (9) aturan yang harus dilakukan dalam defense, yaitu :

1. Cimmunication

2. Ball Pressure

3. Positioning

4. Jump to The Ball

5. Quick Help and Early Recovery

6. Dead Front Post

7. Stop Swing

8. Cover Down

9. Block Out and Rebound.

Dari sembilan aturan diatas, diharapkan semua pemain dapat mengerti esensi dari apa yang dimaksud dengan kesembilan aturan defense tersebut.

Dengan mengetahui aturan diatas, sistem apapun yang akan diterapkan oleh pelatih menjadi akan lebih mudah dimengerti, karena para pemain sudah mengetahui hal-hal apa yang harus dilakukan ketika sedang bertahan. selanjutnya penulis akan membahas beberapa jenis pertahanan yang sering dilakukan, diantaranya seperti man to man defense, zone defense, mix defense, dan zone press.

a. Pertahanan satu lawan satu

Pertahanan satu lawan satu mengharuskan setiap pemain bertahan menjaga atau menempel satu pemain penyerang.13 Dalam pertahanan satu lawan satu, kelima pemain bertahan harus berusaha melindungi ring basket mereka sepanjang pertandingan,. Untuk memulai sistem pertahanan ini pemain bertahan harus menerapkan attacking defense kepada pemain yang menguasai bola, dengan mempersulit pemain penyerang melakukan dribbling, passing, ataupun melakukan shooting. Dari pernyataan diatas dapat disimpulkan, tanggung jawab utama pemain bertahan adalah tidak membiarkan pemain penyerang melakukan dribble-drive menuju ke ring basket atau melakukan jump shoot secara terbuka, dan biasanya dalam pertahanan satu lawan satu para pemain bertahan disesuaikan dengan para penyerang berdasarkan, kecepatan, posisi, tinggi badan, dan kemampuan.

\section{b. Pertahanan zona}

Didalam pertahanan daerah setiap pemain mendapat tugas untuk mempertahankan daerah tertentu di dalam lingkungan lapangan pertahanannya.14 Tanggung jawab utama dari pemain bertahan zona adalah mencegah lawan mencetak angka dari areanya. Jenis-jenis bentuk sistem pertahanan zona beserta kekuatan dan kelemahannya :

1. Jenis pertahanan zona $2-1-2$

2. Jenis pertahanan zona $2-3$

3. Jenis pertahanan zona $3-2$

4. Jenis pertahanan zona 1-2-2

5. Jenis pertahanan zona 1-3-1

6. Jenis pertahanan zona 2-2-1.

Jenis pertahanan zona 2-1-2, Jenis pertahanan ini sangat kuat di daerah pivot dan di daerah rebound, tetapi lemah di daerah samping sisi-sisi forwards. 17 Dengan meletakan 2 pemain di dekat ring basket, pada sistem pertahanan ini sangatlah cocok untuk melawan tim yang memiliki big man yang kuat. Ketika pemain big man dari tim penyerang mendapatkan bola didaerah 3 detik maka dengan sigap pemain yang dekat dengan ring dapat menutup pergerakan dari pemain tersebut. Kemudian apabila pemain penyerang ada yang melakukan shooting dari outside dan gagal, maka kedua pemain bertahan yang berada di bawah dapat melakukan rebound. Jenis pertahanan zona 2-3 Pertahanan ini sangat kuat di daerah kedua sudut garis akhir dan di daerah di bawah basket serta kekuatan rebound besar. Kelemahannya terletak di daerah post dekat (high post) dan di daerah forwards. Biasanya pada sistem pertahanan ini cenderung musuh.

\section{c. Pertahanan kombinasi}

Unsur-unsur pertahanan satu lawan satu dan pertahanan zona bisa digabungkan untuk menciptakan sebuah pertahanan yang disebut pertahanan kombinasi. Pertahanan kombinasi yang paling umum adalah box and one dan triangle and two. Box and one biasanya digunakan untuk menghadapi 
lawan yang mempunyai satu sasaran utama mencetak point. Empat pemain bertahan membentuk sebuah kotak atau persegi di tepi area 3 detik, sedangkan pemain bertahan kelima melakukan pertahanan satu lawan satu menghadapi pemain penyerang utama lawan.

Pada sistem pertahanan kombinasi box and one ini biasanya digunakan apabila ada pemain lawan yang sangat baik dalam mencetak point, sehingga harus ada satu pemain bertahan yang menjaga dan membayangi pemain tersebut kemana pun dia bergerak. Diharapkan dengna taktik ini tim lawan akan mengalami score less atau tidak mencetak angka dan tim bertahan dapat menyerang dengan baik dan mencetak point.

Adapun jenis pertahanan kombinasi lainnya, yang dimana kali ini ada dua pemain yang akan dijaga satu lawan satu oleh pemain bertahan. Sistem pertahanan tersebut adalah triangle and two. Triangle and two biasanya digunakan untuk menghadapi lawan yang memiliki dua sasaran utama mencetak angka. Tiga pemain bertahan membentuk segitiga zona di dalam area tiga detik untuk melindungi ring basket, sedangkan dua pemain lain menempel dua sasaran utama pencetak angka lawan.

Seperti dengan sistem pertahanan box and one, dari ke lima pemain bertahan ada beberapa pemain yang melakukan sistem pertahanan zona dan ada yang melakukan pertahanan satu lawan satu. Tiga orang yang melakukan pertahanan zona membuat formasi segitiga didaerah tiga detik, dan dua pemain bertahan lainnya menerapkan pertahanan satu lawan satu kepada pemain penyerang yang dianggap berbahaya dan memiliki kemampuan mencetak angka yang baik. Tugas dari tiga penjaga itu adalah menjaga area mereka dan membantu bertahan ketika ada pemain penyerang yang memasuki area dengan membawa bola.

\section{d. Zone press Defense}

Prinsip paling mendasar dari sistem pertahanan ini adalah menaikan atau memperluas daerah pertahanan hingga setengah, tiga perempat, dan bahkan satu lapangan penuh. Tujuan utama pertahanan ini adalah untuk menghasilkan perpindahan bola akibat umpan yang buruk atau pelanggaran 8 detik, yang keduanya menghasilkan bola untuk tim bertahan.

Untuk semua jenis pertahanan zona pada dasarnya dapat digunakan pada sistem pertahanan menekan ini, prinsipnya adalah menaikan ataumemperluas daerah pertahanan zona menjadi setengah, tiga perempat, dan bahkan satu lapangan. Namun jenis yang umum digunakan seperti 1-2-1-1 full court press, 2-2-1 full court press, 1-2-2 zone press, 3-2 zone press, 2-3 zone press, dan 1-3-1 zone press.

Zone press dengan luas pertahanan satu lapangan juga dapat disebut full court press, namun dengan catatan bahwa prinsip yang digunakan adalah zone defense dimana setiap pemain hanya bertanggung jawab dengan daerah yang djaganya dan selanjutnya bergerak atau berotasi sesuai prinsip yang ada. Namun ada juga yang dinamakan man to man full court press ini juga merupakan sistem pertahanan satu lapangan penuh, namun sistem in menggunakan prinsip penjagaan satu lawan satu, dimana setiap pemain bertanggung jawab menjaga satu pemain penyerang. Dibawah ini beberapa contoh sistem pertahanan zone press yang sering digunakan.

Dalam 1-2-1-1 full court press, pemain bertahan berusaha menciptakan perpindahan bola dengan berusaha memaksa lawan untuk mengumpan bola lemparan ke dalam ke sudut maupun tepi lapangan, kemudian menjebak pemain penyerang yang sedang menguasai bola. Berikut merupakan gambar formasi 1-2-1-1 full court press. 


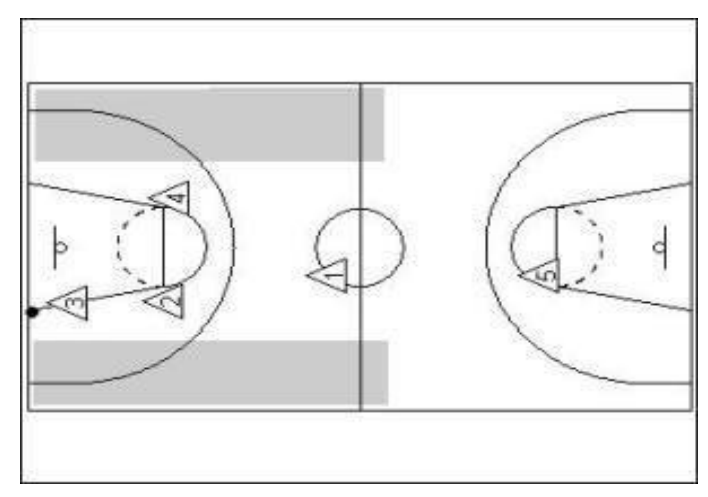

Gambar 1. sistem pertahanan daerah 1-2-1 Sumber :

www.funtionalbasketballcoaching.com

Segitiga dengan nomer tiga melakukan penjagaan terhadap pemain penyerang yang menguasai bola di luar lapangan. Dengan tujuan agar penyerang hanya dapat melakukan passing ke sisi sebelah kana atau kiri, sedangkan segitiga nomer 2 dan 4 bersiap untuk bergerak kearah bola di lempar oleh pemain penyerang yang ada di luar lapangan.

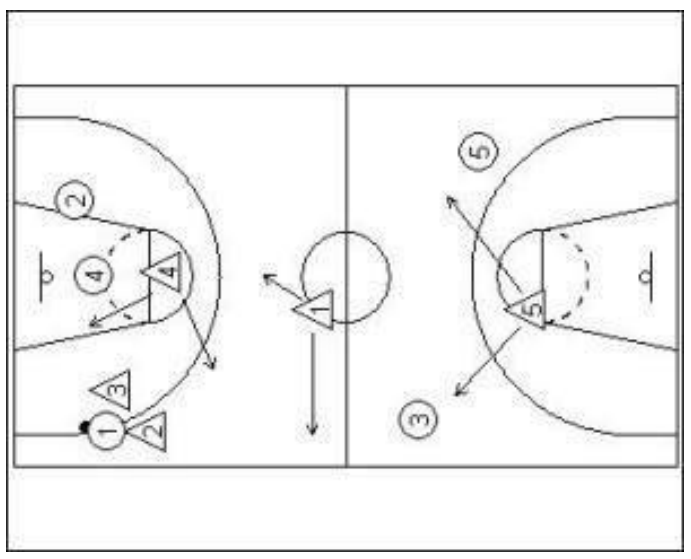

Gambar 2. Perubahan bentuk pertama daro sistem pertahanan daerah 1-2-1

Sumber :

www.funtionalbasketballcoaching.com

Pada gambar 2, pemain yang berada di luar lapangan mengoper bola ke pemain nomer 1, maka secara otomatis pemain bertahan nomer 2 segera menutup pergerakan nomer satu dan pemain bertahan nomer 3 bergerak ke arah pemain penyerang nomer 1 untuk melakukan double team kepada pemain penyerang nomer 1 . Pada saat dua orang melakukan trap atau double team, maka tiga pemain lainnya membentuk rectangular.

Situasi yang terjadi apabila tim penyerang yang di jaga oleh dua orang atau double team dapat memberikan operan ke teman satu timnya, maka ada beberapa kemungkinan yang dapat di manfaatkan, pertama ketika bola yang diberikan melambung maka pemain bertahan lain dapat melakukan intercept, dan apabila pemain bertahan telat untuk melakukan intercept maka cukup bagi pemain bertahan sampai dengan cepat untuk menutup dan melakukan penjagaan terhadap pemain penyerang yang mendapatkan operan tersebut.

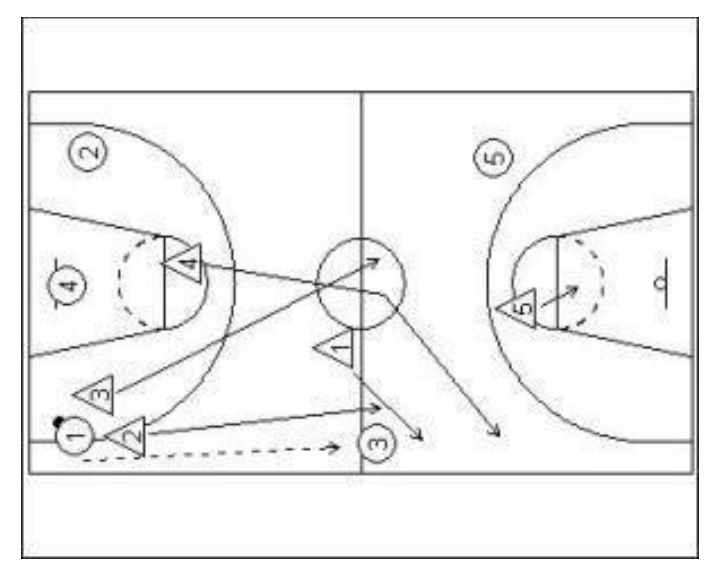

Gambar 3. Perubahan bentuk kedua dari sistem pertahanan daerah 1-2-1

Sumber :

www.funtionalbasketballcoaching.com

Pada gambar 3, pemain penyerang nomer 1 berhsil melakukan pasing ke pemain penyerang nomer 3 , maka untuk pemain yang berada dekat dengan pemain nomer 3 memiliki pilihan untuk melakukan intercept atau melakukan penjagaan dengan cepat untuk menghalau pergerakan pemain penyerang nomer 3 , dan untuk pemain bertahan yang semula melakukan double team segera berpencar menempati area yang kosong. Pemain bertahan nomer 2 dengan cepat membantu pemain bertahan nomer 1 untuk melakukan double team kembali, sedangkan pemain nomer 3 bergerak cepat untuk menjaga area tengah. 
Zone press defense 1-2-2 atau 3-2 zone press merupakan sistem pertahanan yang mudah untuk diajarkan, dan juga aman diterapkan dalam pertandingan karena nemempatkan beberapa pemain yang selalu menjaga daerah belakang untuk mencegah lay up lawan.27 Seperti jenis zone press defense yang lainnya, dengan sistem pertahanan ini pemain bertahan harus memaksa pemain penyerang melakukan passing ke sisi lapangan.

Selanjutnya pada gambar 4 akan diperlihatkakan pergerakan dari sistem pertahanan 1-2-2 zone press, dimana pada gambar ini akan dijelaskan secara jelas bagaimana sistem pertahanan ini berjalan, dan
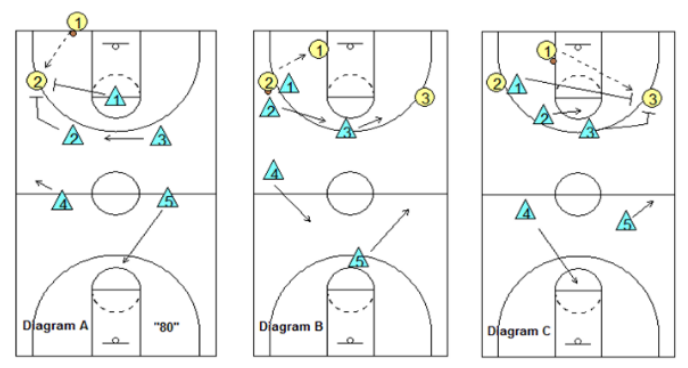

Gambar 4. Bentuk dan pergerakan zone press defence 1-2-2

Sumber: www.tutorialbasket.com

Pada gambar 4 diagram A, dijelaskan ketika pemain penyerang mengoper bola ke sisi sebelah kanan, maka pemain bertahan nomer 1 bertanggung jawab untuk memberikan tekanan kepada lawan yang sedang menguasai bola dan mencegah setiap penetrasi yang mengarah ke bagian tengah lapangan, yang akhirnya pemain bertahan nomor 1 dan 2 akan melakukan trap kepada pemain penyerang nomer 2. Sedangkan pemain bertahan dengan nomer 3 bertanggung jawab untuk mencegah setiap passing yang mengarah ke tengah lapangan, kemudaian pemain yang berada jauh dari bola seperti pemain bertahan nomer 4 bergerak ke arah half court dan pemain bertahan nomer 5 bergerak turun ke tengah untuk melakukan penjagaan dari operan jauh atau long pass.

Pada diagram B terlihat bola di kembalikan ke pemain penyerang nomor 1 , kemudian pemain bertahan nomor 1 melakukan penjagaan kepada pemain penyerang nomoe 1 sekaligus mencegah bola dapat dioper kembali ke pemain penyerang nomor 2 . Kemudian pemain bertahan nomer 3 perlahan bergeser ke sebelah kanan, dan pemain bertahan nomer 2 bergerak ke tempat posisi sebelum pemain bertahan nomor 3 bergerak.

Pada diagram $\mathrm{C}$ adalah merupakan kejadian ketika ball reversal dari satu sisi ke sisi lain, maka tugas pemain bertahan nomer 3 adalah bertugas menjaga penetrasi dari sisi lapangan, kemudian pemain bertahan nomor 1 bergerak dengan cepat untuk melakukan trap, dan pemain bertahan nomor 2 bertugas mencegah setiap operan ke bagian tengah lapangan, pemain bertahan nomor 5 bergerak ke garis half court, dan pemain bertahan nomor 4 bergerak turun ketengah sebagai pengaman. Pada sistem pertahanan zone press 1-2-2 apabila telah melewati garis half court maka trap dapat dilakukan di pojok-pojok di dekat garis half court, dengan harapan pemain penyerang mendapatkan tekanan dan melakukan kesalahankesalahan sehingga bola dapat dikuasai oleh pemain bertahan.

\section{BOLA BASKET}

Permainan Bola Basket Olahraga permainan bola basket adalah sebuah permainan yang sederhana.3 Permainan ini dimainkan oleh 5 orang setiap tim nya, denganbergantian menyerang dan bertahan. Permainan bola basket dimainkan sebanyak 4 quarter, disetiap quarter biasanya dimainkan selama 10 menit.

Berbeda dengan peraturan NBA yang bermaina selama 12 menit dalam waktu 4 quarter. Selama waktu tersebut pemain yang ada di lapangan melakukan penyerangan dan bertahan secara bergantian, yang akhirnya pada permaianan ini, tim yang ditentukan sebagai pemenang adalah yang mengumpulkan point paling banyak. Ada beberapa definisi yang lain mengatakan :

Permainan bola basket dimainkan oleh 2 tim yang masing-masing terdiri dari 5 pemain. Tujuan dari kedua tim adalah mendapatkan angka dengan memasukan bola ke dalam keranjang lawan dan mencegah lawan mendapatkan angka yang diawasi oleh officials (wasit), tableofficials 
dan seorang pengawas pertandingan. Tim yang mendapatkan angka lebih banyak di akhir pertandingan adalah pemenangnya Pada buku yang berjudul bola basket langkah sukses Hal Wissel mengatakan bahwa, bola basket dimainkan oleh dua tim dengan 5 pemain per tim. Tujuannya adalah mendapatkan nilai dengan memasukan bola ke keranjang dan mencegah tim lain melakukan hal serupa.

Permainan bola basket merupakan keterampilan gerak terbuka. Keterampilan gerak terbuka adalah keterampilan yang dilakukan dalam kondisi lingkungan yang tidak berubah-ubah dan geraknya dilakukan semata mata karena stimulus dari dalam diri pelaku sendiri dan stimulus dari luar. Permainan bola basket sangat cepat perkembangannya dan banyak menarik perhatian semua orang, mulai dari anakanak, remaja, sampai orang tua. Hal ini dibuktikan dari kualitas pengembangan kompetisi semakin banyak di Indonesia yang diadakan sebagai tindakan pembinaan dengan adanya pertandingan antar sekolah (Sekolah Dasar, Sekolah Menengah Pertama, dan Sekolah Menengah Atas), pertandingan perguruan tinggi (Liga Bola Basket Mahasiswa) dari divisi dua sampai ke divisi nasional, pertandingan antar klub dari kategori umur, divisi II sampai divisi I yang berjenjang sampai tingkat liga PBL (Premier Basketball League) dan pertandingan yang paling bergengsi di Indonesia yaitu NBL (National Basketball League).

Menurut bukunya yang berbeda, Bidang III PB Perbasi mengatakan bahwa bola basket adalah permainan yang cepat, dinamis, menarik dan mengagumkan. Perubahan angka yang terjadi setiap menitnya membuat permainan ini menarik. Persinggungan tubuh (body contact) dalam permainan bola basket adalah suatu hal yang pasti terjadi, oleh sebab itu bukan hanya fisik saja yang diperlukan dalam permainan bola basket tetapi mental pun sangat diperlukan. Menurut Edy S.R salah satu filosofi dasar tentang permainan bola basket adalah permainan yang cepat dan dinamis.
Olahraga bola basket juga memiliki karakter sosial tertentu dengan corak permainan yang banyak mengandung unsur "Pura - pura, menipu, dan muslihat". Dari semua nilai yang terdapat dalam permaianan bola basket ada unsur kompetitif yang sangat penting, namun untuk memenangkan pertandingan sebuah tim harus memiliki kualitas betahan dan menyerang sama baiknya. Tim yang dapat menjaga pertahanannya dengan baik akan membuat tim penyerang kesulitan dalam mencetak angka, dan ketika pertahanan sebuah tim dapat membuat tim penyerang melakukan kesalahan, maka dengan cepat pemain bertahan dapat melakukan finishing dengan cepat dengan serangan cepat atau fast break. Secara langsung hal terpenting sebelum melakukan penyerangan adalah melakukan pertahanan dengan sebaik-baiknya.

\section{METODE PENELITIAN}

Metode penelitian ini termasuk dalam metode deskriptif dengan teknik pengambilan data observasi/survey. Penelitian ini bermaksud untuk menganalisis sistem pertahanan zone press dan full court press tim bola basket putera UNJ pada kejuaraan STAN Big Ball Tournament 2015.

Teknik dari penelitian ini adalah survey dalam bentuk metode penelitian diantaranya :

1. Observasi bebas dengan melihat langsung.

2. Observasi tertulis dengan chart penelitian yang berisi kolom-kolom tabel dan barisbaris tabel untuk mencatat data.

3. Observasi dengan teknik dokumenter.

$$
\text { Metode observasi diatas }
$$

dikombinasikan sehingga memperoleh data yang nyata, kemampuan dihitung dari setiap defense yang dilakukan, kemudian di tentukan ke dalam kategori sistem pertahanan zone press (3-2 zone press, 2-3 zone press, dan 2-2-1 full court press) yang pada akhirnya di analisis tingkat keberhasilan dan kegagalan sistem pertahanan tersebut. 


\section{HASIL PENELITIAN}

1. Rata-rata keberhasilan sistem pertahanan 3-2 zone press tim bola basket putera UNJ pada STAN Big Ball Tournament 2015.

Data yang diperoleh dari jumlah keseluruhan aktivitas bertahan dengan menggunakan sistem 3-2 zone press adalah sebagai berikut : Keberhasilan sistem pertahanan 3-2 zone press tim bola basket putera UNJ dalam STAN Big Ball Tournament 2015 sebanyak 52,31 \% dan mengalami kegagalan 47,69 \%. Dalam grafik pie dapat digambarkan sebagai berikut.

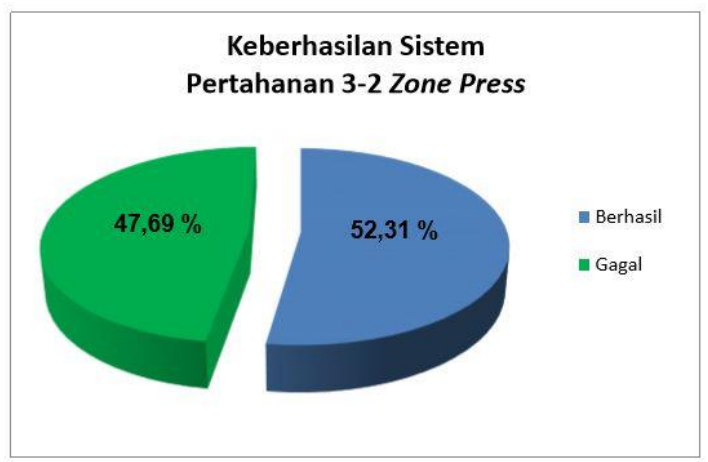

Gambar 5 : Grafik pie rata-rata keberhasilan sistem pertahanan 3-2 zone press tim bola basket putera UNJ pada STAN Big Ball Tournament 2015.

2. Rata-rata keberhasilan sistem pertahanan 2-3 zone press tim bola basket putera UNJ dalam STAN Big Ball Tournament 2015.

Data yang diperoleh dari jumlah keseluruhan aktivitas bertahan dengan menggunakan sistem 2-3 zone press adalah sebagai berikut : Keberhasilan sistem 2-3 zone press tim bola basket putera UNJ dalam STAN Big Ball Tournament 2015 sebanyak $42,86 \%$ dan mengalami kegagalan sebanyak $57,14 \%$. Dalam grafik pie dapat digambarkan sebagai berikut.

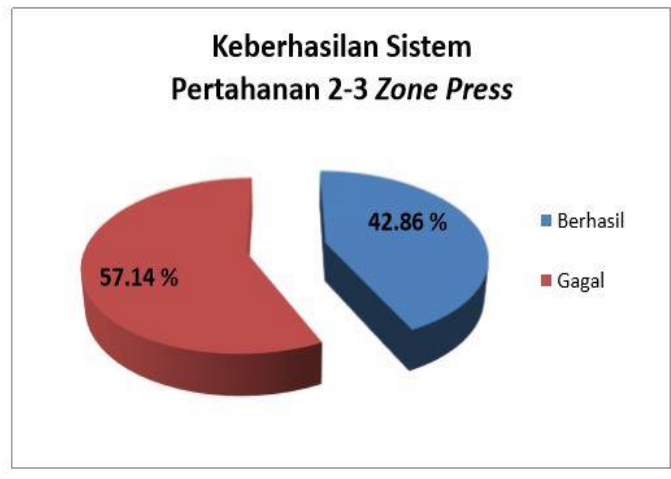

Gambar 6 : Grafik pie rata-rata keberhasilan sistem pertahanan 2-3 zone press tim bola basket putera UNJ pada STAN Big Ball Tournament 2015.

3. Rata-rata keberhasilan sistem pertahanan 2-2-1 full court press tim bola basket putera UNJ dalam STAN Big Ball Tournament 2015.

Data yang diperoleh dari jumlah keseluruhan aktivitas bertahan dengan menggunakan sistem 2-2-1 full court press adalah sebagai berikut : Keberhasilan sistem 2-2-1 full court press tim bola basket putera UNJ dalam STAN Big Ball Tournament 2015 sebanyak 62,16\% dan mengalami kegagalan sebanyak 37,84\%. Dalam grafik pie dapat digambarkan sebagai berikut.

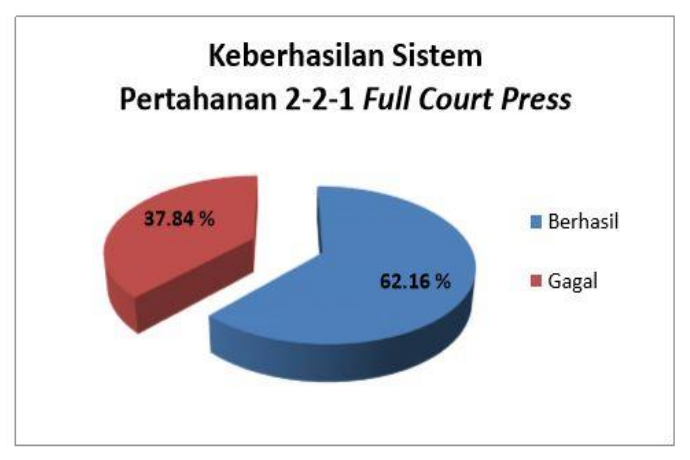

Gambar 7 : Grafik pie rata-rata keberhasilan sistem pertahanan 2-2-1 full court press tim bola basket putera UNJ pada STAN Big Ball Tournament 2015. 
Tabel 1 : Hasil analisis data keseluruhan keberhasilan dan kegagalan sistem pertahanan tim bola basket putera UNJ pada STAN Big Ball Tournament 2015 dengan menggunakan zone press.

\begin{tabular}{|c|l|c|c|c|c|c|c|}
\hline \multirow{2}{*}{ NO } & \multirow{6}{|c|}{ UNJ } & \multicolumn{5}{|c|}{ AKTIVITAS ZONE PRESS } \\
\cline { 3 - 8 } & & \multicolumn{2}{|c|}{$\mathbf{3 2}$} & \multicolumn{2}{|c|}{$\mathbf{2 3}$} & \multicolumn{2}{c|}{$\mathbf{2 2 1}$} \\
\cline { 3 - 8 } & & Berhasil & Gagal & Berhasil & Gagal & Berhasil & Gagal \\
\hline 1 & STMKG & 9 & 3 & 0 & 0 & 4 & 1 \\
\hline 2 & USAKTI & 21 & 17 & 0 & 2 & 3 & 3 \\
\hline 3 & UNHAS & 10 & 17 & 5 & 9 & 1 & 4 \\
\hline 4 & STAN & 9 & 5 & 4 & 3 & 6 & 3 \\
\hline 5 & ATMA & 11 & 12 & 2 & 2 & 3 & 3 \\
\hline 6 & ITB & 8 & 8 & 1 & 0 & 6 & 0 \\
\hline & Jumlah & $\mathbf{6 8}$ & $\mathbf{6 2}$ & $\mathbf{1 2}$ & $\mathbf{1 6}$ & $\mathbf{2 3}$ & $\mathbf{1 4}$ \\
\hline \multicolumn{2}{|c|}{ Prosentase } & $\mathbf{5 2 . 3 1} \%$ & $\mathbf{4 7 . 6 9 \%}$ & $\mathbf{4 2 . 8 6 \%}$ & $\mathbf{5 7 . 1 4} \%$ & $\mathbf{6 2 . 1 6 \%}$ & $\mathbf{3 7 . 8 4 \%}$ \\
\hline
\end{tabular}

Dari tabel diatas ada beberapa hal yang menarik untuk dibahas, yang pertama adalah jumlah penerapan sistem pertahanan 3-2 zone press sebanyak 130 kali, perbandingan yang sangat jauh antara 2-3 zone press yang hanya sebanyak $28 \mathrm{kali}$, dan 2-2-1 full court press sebanyak 37 kali.

Dari angka tersebut menandakan pelatih tim putera UNJ lebih cenderung menerapkan sistem pertahanan tersebut dibanding dua sistem yang lain, menurut analisis peneliti ada dua hal mengapa 32 zone press menjadi pilihan pelatih UNJ dalam menerapkan sistem pertahanan. Pertama adalah faktor fisik, dengan menerapkan sistem ini kondisi fisik pemain UNJ lebih terjaga, sehingga pemain UNJ masih dapat bermain dengan baik sampai pada quarter 4, dibanding dengan menggunakan 2-2-1 full court press yang mungkin jauh menguras tenaga ketika sistem ini diterapkan.

Yang kedua adalah faktor keuntungan dimana ketika pemain UNJ berhasil melakukan intercept, maka pemain bertahan tim lawan lebih sedikit dibanding pemain UNJ, dikarenakan pemain yang tadinya menyerang masih ada disisi front court, tentu untuk kembali ke back court membutuhkan waktu, sehingga pemain UNJ akan lebih mudah mencetak angka, karena kemungkinan yang terjadi adalah jumlah pemain penyerang sebanyak dua orang, dan melawan satu orang pemain bertahan.

Kemudian hal yang menarik kedua adalah tantang 2-3 zone press, dimana sistem ini sangat jarang digunakan tim putera UNJ namun tingkat kegagalannya lebih tinggi dari keberhasilan. Dengan kegagalan sebesar 57,14\% dan keberhasilan 42,86\% ini menjadi pertanyaan besar mengapa sistem ini masih digunakan, hal ini terlihat jelas pada pertandingan UNJ vs UNHAS dimana dari 14 kali percoban hanya berhasil sebanyak 5 kali, untuk itu didapatkan beberapa analisis peneliti yang dimana ada hal yang harus diperhatikan apabila sistem ini ingin diterapkan pada sebuah pertandingan.

Pertama adalah di Indonesia sudah banyak pemain yang bisa menembak dari jarak jauh, ini tentu menjadi kelemahan dari sistem ini. Ketika dua pemain bertahan didepan sangat sulit menghalau tembakan yang dilakukan di atas garis three point. Pada akhirnya banyak tim lawan melakukan tembakan di spot tersebut. Selanjutnya hal yang perlu dipertimbangkan adalah bagaimana pemain lawan tidak dapat melakukan operan dengan mudah sehingga membuat pemain bertahan berada pada unbalancing defense, ketika ini terjadi pasti ada salah satu pemain lawan yang kosong dan akhirnya dapat melakukan tembakan tanpa penjagaan, dan ini pula yang terjadi pada tim UNJ pada kejuaran ini, harusnya memang dalam penerapan sistem 2-3 zone press ini tim bertahan mencoba menekan lawan untuk tidak dapat melakukan operan-operan dengan mudah, seperti pada sistem pertahanan 2-3 zone press yang diterangkan pada kerangka berpikir, dimana pemain lawan akan sulit melakukan operan dengan mudah karena prinsip attacking defense benar-benar diterapkan, attacking defense itu sendiri adalah situasi dimana pergerakan penyerang ditentukan oleh pemain bertahan.

Hal yang terakhir adalah tentang 2-2-1 full court press, berdasarkan statistik efektivitas dari sistem ini paling tinggi dibanding dua sistem pertahanan yang lain, tapi mengapa sistem ini jarang digunakan oleh tim UNJ dalam bertahan, dan ini adalah sebuah pertanyaan besar. Berdasarkan analisis peneliti, jawaban dari pertanyaan itu adalah kebalikan dari mengapa 3-2 zone press sering digunakan. Kalau 3-2 zone press bisa menghemat 
tenaga, 2-2-1 full court press sangatlah menguras tenaga, sehingga ketika masuk di quarter 4, tim UNJ sudah mengalami penurunan performance karena tingkat kelelahan yang berarti. Dan yang terakhir adalah faktor kesulitan mencetak angka ketika UNJ berhasil merebut bola dengan 22-1 full court press, ini dikarenakan jumlah pemain bertahan sama banyaknya dengan pemain penyerang, sangat berbeda dengan 3-2 zone press, dimana pemain bertahan jauh lebih sedikit, dengan 2 alasan dari hasil analisis peneliti, ini menjadi jawaban mengapa 2-2-1 full court press jarang digunakan walaupun efektivitas dari sistem ini lebih tinggi dibanding 2-3 zone press atau 3-2 zone press.

Selanjutnya peneliti akan mencoba menganalisis keberhsilan dan kegagalan 3-2 zone press, 2-3 zone press, dan 2-2-1 full court press dengan memasukan kriteria keberhasilan dan kegagalan yang kemudian dijabarkan pada bentuk tabel.

Tabel 2 : Hasil analisis data keberhasilan dan kegagalan sistem pertahanan tim bola basket putera UNJ pada STAN Big Ball

Tournament 2015 dengan menggunakan 32 zone press.

\begin{tabular}{|l|l|}
\hline \multicolumn{1}{|c|}{ Keberhasilan } & \multicolumn{1}{|c|}{ Kegagalan } \\
\hline $\begin{array}{l}\text { Keberhasilan 3-2 zone } \\
\text { pressdengan kriteria } \\
\text { keberhasilan intercept } \\
\text { sebanyak } 40 \text { kali, dengan } \\
\text { prosentase } 58,82 \%,\end{array}$ & $\begin{array}{l}\text { kegagalan sistem pertahanan 3-2 } \\
\text { zone press pada kriteria fault } \\
\text { sebanyak 11 kali, dengan }\end{array}$ \\
\hline $\begin{array}{l}\text { keberhasilan pada kriteria } \\
\text { error pass sebanyak 12 kali, } \\
\text { dengan prosentase } 17,65 \%,\end{array}$ & $\begin{array}{l}\text { Kegagalan kriteria open shoot } \\
\text { sebanyak 27 dengan prosentase } \\
43,55 \%\end{array}$ \\
\hline $\begin{array}{l}\text { Kriteria yang ketiga yaitu } \\
\text { air ball sebanyak 4 kali, } \\
\text { dengan prosentase 5,88 \%, }\end{array}$ & $\begin{array}{l}\text { Kriteria yang ketiga yaitu long } \\
\text { pass sebanyak 3 kali, dengan } \\
\text { prosentase 4,84 \%, }\end{array}$ \\
\hline $\begin{array}{l}\text { kriteria yang terakhir } \\
\text { yaitu violation sebanyak 12 } \\
\text { kali keberhasilan, dengan } \\
\text { prosentase } 17,65 \% .\end{array}$ & $\begin{array}{l}\text { dan yang terakhir kriteria } \\
\text { kegagalan sistem pertahanan 3-2 } \\
\text { zoness yaitu point, } \\
\text { sebanyak 21 kali dengan } \\
\text { prosentase 33,87 \%. }\end{array}$ \\
\hline
\end{tabular}

Berdasarkan table diatas, maka dapat diambil kesimpulan untuk keberhasilan dalam menerapkan sistem pertahanan tim bola basket putera UNJ lebih banyak berhasil dengan melakukan intercept yaitu sebanyak 40 kali dengan prosentase 58,82
$\%$, hal ini menandakan pada sistem pertahanan ini agresifitas, dan kemampuan membaca bola dalam memotong operan musuh sudah baik. Namun dari sistem pertahanan ini masih juga banyak kekurangan, terlihat dari jumlah kegagalan dari kriteria open shoot sebanyak 27 kali dengan prosentase $43,55 \%$, ini menandakan tim lawan dapat melakukan tembakan dengan bebas tanpa penjagaan, hal ini bisa terjadi karena ada beberapa faktor, yang pertama pemain UNJ yang bertugas menjadi orang terdepan dalam sistem pertahanan ini tidak melakukan attacking deffense atau istilah dalam bola basket yaitu push them to drible. Dari analisis data ini maka pelatih mendapatkan hasil evaluasi yang jelas terkait sistem pertahanan ini, sehingga selanjutnya untuk perbaikan dan peningkatan keberhasilan dalam penerapan sistem ini dapat dilakukan latihan-latihan yang langsung menjurus pada bagian atau sisi terlemah pada sistem pertahanan ini.

Tabel 3 : Hasil analisis data keberhasilan dan kegagalan sistem pertahanan tim bola basket putera UNJ pada STAN Big Ball

Tournament 2015 dengan menggunakan 2-

\section{3 zone press.}

\begin{tabular}{|l|l|}
\hline \multicolumn{1}{|c|}{ Keberhasilan } & \multicolumn{1}{|c|}{ Kegagalan } \\
\hline $\begin{array}{l}\text { Keberhasilan sistem } \\
\text { pertahanan 2-3 zone press } \\
\text { dengan kriteria keberhasilan } \\
\text { intercept sebanyak 3 kali, } \\
\text { dengan prosentase 25\%, }\end{array}$ & $\begin{array}{l}\text { kegagalan sistem pertahanan } \\
2-3 \text { zone press pada kriteria } \\
\text { fault sebanyak 1 kali, dengan } \\
\text { prosentase 6,25\%, }\end{array}$ \\
\hline $\begin{array}{l}\text { keberhasilan pada kriteria } \\
\text { error pass sebanyak 1 kali, } \\
\text { dengan prosentase 8,4\%, }\end{array}$ & $\begin{array}{l}\text { Kegagalan kriteria open } \\
\text { shoot sebanyak 6 kali, } \\
\text { dengan prosentase 37,5\%. }\end{array}$ \\
\hline $\begin{array}{l}\text { Kriteria yang ketiga yaitu air } \\
\text { ballsebanyak kali, } \\
\text { dengan prosentase 33,3\%, }\end{array}$ & $\begin{array}{l}\text { Kriteria yang ketiga yaitu } \\
\text { longpass dengan prosentase }\end{array}$ \\
\hline $\begin{array}{l}\text { yang terakhir } \\
\text { kriteria dengan } \\
\text { yaitu violation sebanyak 4 kali } \\
\text { keberhasilan, } \\
\text { prosentase 33.3\%. }\end{array}$ & $\begin{array}{l}\text { dan yang terakhir } \\
\text { kriteria kegagalan sistem } \\
\text { pertahanan 2-3 zone } \\
\text { press yaitu } \\
\text { point,sebanyak 9 kali } \\
\text { dengan prosentase 56,25\%. }\end{array}$ \\
\hline
\end{tabular}

Berdasarkan data yang diuraikan diatas, maka dapat diambil kesimpulan untuk keberhasilan dalam menerapkan sistem pertahanan 2-3 zone press tim bola basket putera UNJ lebih banyak berhasil karena lawan melakukan air ball sebanyak 4 kali dengan prosentase $33,3 \%$ dan 
violatioan yang dilakukan lawan sebanyak 4 kali denga prosentase $33,3 \%$, perlu diketahui dalam penerapan sistem ini memang diharapkan pemain lawan melakukan outside shoot dan melakukan double team di area corner, dengan menempatkan pemain tertinggi sistem pertahanan ini berhasil membuat lawan sulit melakukan outside shoot dan akhirnya bola tidak sampai menyentuh ring atau yang biasa disebut air ball, kemudian violation yang dilakukan tim lawan kebanyakan dikarenakan penjagaan dua pemain terhadap satu orang atau biasa yang dikenal dengan istilah double team memberikan tekanan yang luar biasa terhadap tim lawan.

Namun apabila dlihat dari tingkat keberhasilan dan kegagalan lebih banyak sistem ini mengalami kegagalan, dengan perbandingan $42,86 \%$ keberhasilan dan $57,14 \%$ untuk kegagalan. Dari data kegagalan dalam penerapan sistem ini ada 2 kriteria yang memeiliki prosentase yang besar, diantaranya open shoot sebesar 37,5 $\%$ dan point $56,25 \%$. Hasil ini menunjukan bahwa ketika tim lawan melakukan operanoperan yang cepat dan disisi lain pemaint tertinggi atau big man tidak dapat bergerak secepat mungkin, maka ada kesempatan ketika pemain big man telat untuk menutup pemain lawan dan akhirnya mendapatkan open shoot disitulah celah mereka untuk mencetak angka.

Permasalahan ini jelas harus langsung direspon oleh pelatih, bagaimana selanjutnya mobilitas pemain big man ini bisa semakin baik dengan memiliki foot work yang baik dalam bertahan sehingga kecepatan bergerak dalam menjaga lawan semakin baik.
Tabel 4: Hasil analisis data keberhasilan dan kegagalan sistem pertahanan tim bola basket putera UNJ pada STAN Big Ball

Tournament 2015 dengan menggunakan 22-1 full court press.

\begin{tabular}{|c|c|}
\hline Keberhasilan & Kegagalan \\
\hline $\begin{array}{l}\text { Keberhasilan sistem pertahanan } \\
2-2-1 \text { full court press dengan } \\
\text { kriteria keberhasilan intercept } \\
\text { sebanyak } 15 \text { kali, dengan } \\
\text { prosentase } 65,22 \% \text {, }\end{array}$ & $\begin{array}{l}\text { kegagalan sistem } \\
\text { pertahanan } 2-2-1 \text { full court } \\
\text { press pada kriteria fault } \\
\text { sebanyak } 10 \text { kali, dengan } \\
\text { prosentase } 71,43 \%,\end{array}$ \\
\hline $\begin{array}{l}\text { keberhasilan pada kriteria error } \\
\text { pass sebanyak } 5 \text { kali, } \\
\text { dengan prosentase } 21,74 \% \text {, }\end{array}$ & $\begin{array}{l}\text { Kegagalan kriteria open } \\
\text { shoot sebanyak } 3 \quad \text { kali, } \\
\text { dengan prosentase } 21,43 \% .\end{array}$ \\
\hline $\begin{array}{l}\text { Kriteria yang ketiga yaitu air } \\
\text { ball sebanyak } 1 \text { kali, dengan } \\
\text { prosentase } 4,34 \% \text {, }\end{array}$ & $\begin{array}{l}\text { Kriteria yang ketiga yaitu } \\
\text { long pass sebanyak } 1 \text { kali, } \\
\text { dengan prosentase } 7,14 \% \text {, }\end{array}$ \\
\hline $\begin{array}{l}\text { Kriteria yang terakhir } \\
\text { yaitu violation sebanyak } 2 \text { kali } \\
\text { keberhasilan, } \\
\text { prosentase } 8,70 \% .\end{array}$ & $\begin{array}{l}\text { dan yang terakhir } \\
\text { kriteria kegagalan point } \\
\text { dengan prosentase } 0 \% \text {. }\end{array}$ \\
\hline
\end{tabular}

Keberhasilan dalam melakukan intercept memiliki prosentase terbesar dari keempat kriteria keberhasilan, ini menandakan sistem ini berhasil membuat tim lawan mendapatkan tekanan sehingga banyak operan yang dapat di cegah oleh pemain UNJ untuk mengembalikan keadaan. Namun pada sistem pertahanan ini juga rentan sekali terjadi fault, terlihat dengan prosentase kegagalan pada kriteria fault sangat besar yaitu $71,43 \%$, resiko menerapkan sistem pertahanan ini memang akan banyak terjadi fault apabila agresifitas dalam bertahan tidak dapat di management dengan baik, ada beberapa kesepakatan yang harus di ikuti seperti, no stealing, no reaching in, ketika memang hal itu dilanggar banyak pemain dari UNJ terkena fault, ini harus menjadi perhatian bagi pelatih untuk benar-benar mengitruksikan pemainnya untuk menjalankan sistem ini sesuai dengan konsep yang disepakati. 


\section{KESIMPULAN}

1. Keberhasilan sistem pertahanan 3-2 zone press tim bola basket putera Universitas Negeri Jakarta pada STAN Big Ball Tournament 2015 sebesar 52,31\% dan mengalami kegagalan sebesar 47,69\%.

2. Keberhasilan sistem pertahanan 2-3 zone press tim bola basket putera Universitas Negeri Jakarta pada STAN Big Ball Tournament 2015 sebesar $42,86 \%$ dan mengalami kegagalan sebesar $57,14 \%$.

3. Keberhasilan sistem pertahanan 2-2-1 full court press tim bola basket putera Universitas Negeri Jakarta pada STAN Big Ball Tournament 2015 sebesar $62,16 \%$ dan mengalami kegagalan sebesar $37,84 \%$.

4. Sistem pertahanan 2-2-1 full court press memberikan prosentase keberhasilan yang tinggi pada penampilan tim bola basket putera Universitas Negeri Jakarta dalam STAN Big Ball Tournament 2015 yaitu sebesar $62,16 \%$, dibandingkan dengan sistem pertahanan 3-2 zone press sebesar $52,31 \%$ dan 2-3 zone press sebesar $42,86 \%$.

\section{SARAN}

1. Dari hasil penelitian ini ada beberapa saran yang menjadi perhatian, yang pertama adalah menurut Jean Pierre Balduin, Instruktur IOC yang pernah memberikan penataran pelatih di Indonesia mengatakan, tidak ada defense yang paling baik, yang ada hanyalah defense yang paling berguna untuk sebuah tim. 3-2 zone press dan 2-2-1 full court press terlihat menjadi pilihan yang baik, karena tingkat keberhasilannya yang cukup tinggi yaitu $52,31 \%$ dan $62,16 \%$. Walaupun 2-2-1 full court press memiliki prosentase keberhasilan tertinggi namun dalam penerapan sistem ini ada banyak hal yang harus diperhatikan, diantaranya faktor fisik, irama permainainan, dan keuntungan. itulah fungsi pelatih untuk membaca permainan dan cepat mengambil keputusan apa yang harus dilakukan oleh timnya disaat sedang bertanding.
2. Penjabaran diatas juga menjelaskan tugas pelatih adalah bagaimana selanjutnya melakukan evaluasi untuk nantinya dapat diterapkan pada saat latihan guna memperbaiki kriteria kegagalan dalam bertahan yang sering dilakukan dalam sistem pertahanan zone press, baik itu 32 zone press, 2-3 zone press, dan 2-2-1 full court press.

3. Selanjutnya, materi latihan defense harus dijabarkan secara jelas dan terperinci setiap pergerakan dan perpindahan yang dilakukan agar atlet dapat mengerti, dan akhirnya terlatih untuk menempatkan diri sesuai dengan ideal distance atau jarak ideal yang baik ketika sedang melakukan pertahanan dengan sistem ini.

4. Pada lawan yang memiliki kemampuan menyerang yang baik tim ini sering mengalami kegagalan, ini menandakan kemampuan bertahan individu yang masih kurang baik, perlu latihan secara khusus untuk memperbaiki teknik dalam pertahanan satu lawan satu.

5. Komunikasi dalam sistem pertahanan ini menjadi kunci keberhasilan, inilah tugas pelatih yang dimana harus menekankan kepada pemain untuk mampu berkomunikasi kepada temannya katika sedang bertahan.

6. Dan yang paling penting, pelatih juga harus mampu memotivasi tim ini agar mereka dapat menampilkan permainanan terbaik, dengan kerja keras dan team work tim ini akan menjadi kuat.

7. Dan yang terakhir diharapkan pelatih memiliki report tentang evaluasi secara tertulis agar dapat di dokumentasikan, Tentu ini tidak mudah, perlu usaha yang lebih untuk membuat laporan ini secara tertulis agar memang tim ini kedepannya memiliki dokumen tentang progress yang sudah diraih, dan apa yang menjadi evaluasi. Saran terakhir ini hanya menjadi sebuah tambahan dan menjadi harapan penulis, agar kedepannya dalam pergantian pelatih, mereka dapat belajar dari laporan yang dibuat secara tertulis. 


\section{DAFTAR PUSTAKA}

Bidang III PB. PERBASI. Bola Basket untuk Semua. Jakarta: PB. PERBASI, 2006.

Peraturan Resmi Permainan Bola Basket 2004. Jakarta: Bidang III PB. PERBASI, 2005.

Edy Suganda. R. My Basketball Handbook. Jakarta: PT. Grafindo Persada, 2002.

Marta Dinata, Konsep dan Teknik Bermain Bola Basket. Ciputat: Penerbit Cerdas Jaya, 2008

Nasution, S., Metode Research Penelitian Ilmiah. Jakarta: Bumi Aksara, 2011.

Nuril Ahmadi, Permainan Bola Basket. Surakarta: ERA INTERMEDIA, 2007.

Oliver, Jon. Dasar-Dasar Bola Basket. Bandung: PT. Intan Sejati, 2007.

Sugiyono, Cara Mudah Skripsi, Tesis, dan Disertasi, Bandung: Alfabeta, 2014.

Suharsimi Arikunto. Manajemen Penelitian. Jakarta: Rineka Cipta, 2005.

Widiastuti. Belajar Motorik. Jakarta: FIK UNJ, 2003.

Wissel, Hal. Bola Basket Langkah Sukses. Jakarta: PT. Raja Grafindo Persada, 2000.

www.tutorialbasket.com/2010/11/ bentuk dan pergerakan zone press defense 1-2-2.html (diakses 18 Februari 2015, Pukul 17.05 wib) 